\title{
МУЛЬТИМЕДИЙНЫЕ ТЕХНОЛОГИИ В КОНТЕКСТЕ ПРОБЛЕМНОГО МОДЕЛИРОВАНИЯ КАК НОВОГО ПОДХОДА К ОБУЧЕНИЮ
}

\author{
Ветлугина Н.O. ${ }^{1}$, Фоминых M.B. ${ }^{1}$ \\ ${ }^{1}$ ФГАОУ ВО «Российский государственный профессионально-педагогический университет», Екатеринбург, е- \\ mail:vetlugina_no@rambler.ru,fominykh.maria12@yandex.ru
}

Актуальность данной статьи состоит в объяснении необходимости и целесообразности внедрения проблемного моделирования как подхода и выявлении условий применения мультимедиа-технологий в современном образовательном процессе, а именно в условиях дистанционного обучения. Ситуация, связанная с пандемией COVID-19, стала новым явлением для системы высшего образования. Опыт применения мультимедиа-технологий в данном случае представляется весьма актуальным. Очевидно, что в сложившейся ситуации традиционные подходы к обучению в учреждениях профессионального образования недостаточно эффективны, что актуализирует поиски путей совершенствования образовательного процесса. Значение мотивации в обучении трудно переоценить, а проблемное моделирование как инновационный подход обладает огромным мотивационным потенциалом. В статье раскрыты условия проблемного моделирования с точки зрения мотивационного потенциала данного подхода. Выделены условия применения мультимедиа-технологий в рамках проблемного моделирования, a также приведены примеры практико-ориентированных заданий с применением мультимедиатехнологий в условиях проблемного моделирования. Практическая значимость исследования заключается в теоретическом определении авторской концепции проблемного моделирования как подхода; представленные авторские условия использования мультимедийных технологий и практикоориентированных заданий могут быть применены в практике работы со студентами педагогических специальностей.

Ключевые слова: инновации в образовании, мультимедийные технологии, проблемное моделирование, мотивация, обучение иностранному языку.

\section{MULTIMEDIA TECHNOLOGIES IN THE CONTEXT OF PROBLEM MODELING AS A NEW APPROACH TO LEARNING}

\author{
Vetlugina N.O. ${ }^{1}$, Fominykh M.V.1 \\ 1 «Russian state vocational pedagogical University», Ekaterinburg, e-mail: vetlugina_no@rambler.ru, \\ fominykh.marial2@yandex.ru
}

The relevance of this article is to explain the necessity and expediency of introducing problem modeling as an approach and to identify the conditions for the use of multimedia technologies in the modern educational process, namely in the conditions of distance learning. The situation related to the COVID-19 pandemic has become a new phenomenon for the higher education system. The experience of using multimedia technologies in this case seems to be significantly relevant. It is obvious that in the current situation, traditional approaches to training in vocational education institutions are not effective enough, which actualizes the search for ways to improve the educational process. It is difficult to overestimate the importance of motivation in learning, and problem modeling as an innovative approach has a huge motivational potential. The article reveals the conditions of problem modeling from the point of view of the motivational potential of this approach. The conditions for the use of multimedia technologies in the framework of problem modeling are highlighted, and examples of practice-oriented tasks with the use of multimedia technologies in the context of problem modeling are also given. The practical significance of the research lies in the theoretical definition of the author's concept of problem modeling as an approach; the presented author's conditions for the use of multimedia technologies and practice-oriented tasks can be used in the practice of working with students of pedagogical specialties.

Keywords: innovations in education, multimedia technologies, problem modeling, motivation, foreign language teaching.

Современные студенты находятся под влиянием информационных технологий, многие со школы знакомы со средствами мультимедиа, во многих учебных центрах, школах, курсах подготовки к экзаменам имеются проекторы, мультимедийные экраны, интерактивные доски. 
молодежи, а именно у студентов, они занимают первое место. В данной статье авторы рассматривают данный вид технологий как новый элемент системы обучения в контексте проблемного моделирования. Проблемное моделирование - авторский инновационный подход в обучении, основанный на мотивационной базе обучения, обеспечивающий практикоориентированный характер изучения дисциплин профильного цикла учебного плана. Устойчивая мотивация к обучению - залог успешной будущей профессиональной деятельности, что немаловажно в современном обществе, нуждающемся в высококвалифицированных и конкурентоспособных специалистах.

Цель исследования заключается в выявлении необходимости разработки условий применения мультимедиа-технологий и практико-ориентированных заданий в рамках проблемного моделирования как инновационного подхода.

Ведущим подходом к исследованию данной проблемы является обобщение методического и педагогического опыта отечественных и зарубежных ученых. Принцип целостного изучения педагогического процесса позволил комплексно проанализировать проблемное моделирование с применением мультимедиа-технологий в контексте цифровой педагогики как нового направления в педагогической практике. Системный метод применялся с целью изучения отдельных компонентов проблемного моделирования как подхода.

Научная новизна исследования определяется теоретическим обоснованием внедрения в практику системы практико-ориентированных заданий с применением мультимедиатехнологий в рамках проблемного моделирования как инновационного подхода в обучении.

Теоретической базой исследования послужили фундаментальные работы по педагогике и психологии (Ю.К. Бабанского, А.Н. Леонтьева, В.В. Краевского); теории моделирования (Н.В. Борисовой, Н.П. Бусленко, Ю.А. Гастаева, В.Н. Максимовой); теории педагогического проектирования и моделирования (В.П. Беспалько, А.А. Вербицкого, Ю.В. Громыко, М.В. Кларина); современные разработки педагогической науки в области организационных форм обучения (В.В. Краевского); проблема проектирований педагогических технологий (В.П. Беспалько, В.В. Сериковой, М.А. Чошановой); теория готовности к профессиональной деятельности (Г.Н. Жукова, Э.Ф. Зеера, В.А. Сластенина).

\section{Результаты исследования и их обсуждение}

В современном образовательном процессе преподаватели сталкиваются со множеством подходов к обучению, им приходится делать выбор в пользу того или иного подхода, изучать его педагогический и воспитательный потенциал. Проблемное моделирование как инновационный подход базируется на принципах креативной педагогики и проблемно-модельного обучения $[1,2]$. 
Определим проблемное моделирование в обучении как инновационный подход, стимулирующий обучение на основе слияния практико-ориентированной профильной и учебной деятельности, ориентирующий на организацию данной деятельности при помощи построения собственно разработанных моделей в процессе возникновения проблемных ситуаций при осуществлении или моделировании профессиональной деятельности.

Реализация проблемного моделирования связана с удовлетворением потребности человека в профессиональном образовании, обогащающем возможности его осуществления; формированием стратегий личностного и профессионального развития. Именно такой подход позволяет обеспечить конкурентоспособность специалистов.

Эффект достигается решением следующих задач [3, с. 11]:

1) мотивирование личностного и, как следствие, профессионального развития;

2) формирование профессиональной компетентности (а также формирование и развитие специальных и профессиональных компетенций);

3) освоение социально-коммуникативных компетенций;

4) развитие метапрофессиональных качеств (в условиях опережающего образования);

5) формирование индивидуального, новаторского стиля профессиональной деятельности;

6) проектирование альтернативных сценариев своего профессионального будущего;

7) развитие коммуникативных и педагогических способностей [3].

Проблемное моделирование как подход имеет несколько преимуществ в области применения мультимедиа-технологий:

- помогает формировать стиль будущей профессиональной деятельности с точки зрения применения современных инновационных технологий (в данном случае практикоориентированные задания необходимы для будущих учителей иностранного языка, переводчиков, потому что именно эти специалисты нуждаются в регулярном повышении квалификации);

- обладает высоким мотивационным потенциалом (решаемая задача моделирования в учебной деятельности близка к будущей профессиональной ситуации, акцент переносится с обучающей деятельности на познающую, что также играет немаловажную роль в связи с психофизиологическими особенностями студентов, желающих как можно быстрее оказаться в начале своего профессионального пути);

- удачно коррелирует с возможностями мультимедиа-технологий, что крайне актуально в связи со сложившейся ситуацией в мире, связанной с пандемией COVID-19; 
- может применяться в практике профориентационной деятельности и в процессе повышения квалификации.

Следует отметить, что проблемное моделирование успешно внедрено в образовательный процесс ФГАОУ ВО «Российский государственный профессиональнопедагогический университет» на базе кафедры германской филологии. В рамках данного исследовательского проекта по внедрению мультимедиа-технологий в процессе проблемного моделирования как подхода к обучению в практику обучения студентов профильным учебным дисциплинам были внедрены учебные онлайн-курсы на базе платформы Moodle.

Мы трактуем мультимедиа-технологии как средство обучения студентов с применением компьютерных, аудио- и видео-, а также иных digital-устройств с целью наиболее эффективного вовлечения обучающихся в учебный процесс посредством стимулирования интерактивной деятельности. На наш взгляд, данный вид технологий способствует информатизации обучения.

Мы считаем, что проблемное моделирование обладает высоким мотивационным потенциалом. Обязательность изучения иностранного языка, чаще английского, сама по себе способствует развитию дополнительной мотивации, которая, впрочем, не является внутренней. Не изучив язык, учащийся не получает документ об образовании, что базово мотивирует всех учащихся, особенно школьников. Во взрослой жизни, по окончании школы, вуза и иного, человек по-прежнему испытывает потребность в знаниях, однако основными мотивами будут выступать уже потребность в получении знаний, доступных на данном языке, а также возможность и необходимость общения, т.е. коммуникационная направленность как особенность также является своего рода мотивом. Мультимедиа-технологии здесь имеют преимущество перед другими видами технологий, так как $[4,5]$ :

- визуальные и аудиоэффекты помогают лучше усвоить иностранный язык;

- значительную часть занятий можно проводить в интерактивном формате;

- использование индивидуализированных программ обеспечивает применение многоуровневых заданий;

- разработка реально существующих программ в контексте проблемного моделирования успешно помогает в будущей профессиональной деятельности.

На наш взгляд, применение мультимедийных технологий в контексте проблемного моделирования позволяет повысить мотивацию к изучению некоторых дисциплин профессионального цикла (из опыта работы Российского государственного профессиональнопедагогического университета).

Недостаточно простого объяснения или постулирования важности предмета для формирования мотивации. Обучающийся, столкнувшейся с проблемой нехватки знаний по 
изучаемому предмету, будет иметь мотивацию учить предмет, чтобы избежать подобных трудностей в будущем. Мотивация при изучении иностранного языка обладает рядом особенностей, которые обусловлены особенностями изучения любого иностранного языка. Обязательность изучения иностранного языка, чаще английского, сама по себе способствует развитию дополнительной мотивации, которая, впрочем, не является внутренней. Не изучив язык, обучающийся не получает документ об образовании, что базово мотивирует всех учащихся, особенно школьников. Во взрослой жизни, по окончании школы, вуза и т. д., человек по-прежнему испытывает потребность в знаниях, однако основным мотиватором будет выступать уже потребность в получении знаний, доступных на данном языке, а также возможность и необходимость общения, то есть коммуникационная направленность как особенность также является своего рода мотиватором.

На способности языка быть и целью, и средством обучения основаны многие приемы мотивационной деятельности педагогов. Например, чтобы прочитать интересную книгу или посмотреть фильм, чтобы узнать новые факты из жизни кумиров, современные школьники вынуждены изучать язык. Этот факт используют и преподаватели, давая возможность учащимся задействовать свои интересы при изучении языка.

Социокультурная обусловленность иностранного языка как предмета тесно связана с предыдущей особенностью. Мотивацией к изучению в ряде случаев служит не только желание узнать что-либо или пообщаться с кем-то, но и стремление поехать в страну, где говорят на изучаемом языке, так что изучение языка, позволяющее одновременно с грамматикой и прочими формальными составляющими изучать культуру и историю стран, где изучаемый язык активно используется, является дополнительным мотивом [6, 7].

Мотивация сама по себе, как считают многие современные ученые, при изучении иностранного языка может быть сведена к нескольким основным пунктам: стремление к социализации, необходимость познавать новое и, главное, потребность в коммуникации. Данные пункты перекликаются с перечисленными особенностями изучения иностранного языка по сравнению с другими предметами $[4,8,9]$.

Bсе указанные условия не являются специфическими для иностранного языка, они характерны и для других дисциплин. Р.Г. Болбаков отмечает, что мультимедийные технологии служат одним из средств развития мотивации [10]. М.Р. Деньгина акцентирует внимание на удовольствии от обучения как основном мотиве учащегося [11]. Она подчеркивает необходимость учитывать этот фактор и в учебной, и во внеучебной деятельности. Безусловно, именно удовольствие от обучения, которое может быть обусловлено особенностями и условиями, перечисленными выше, является основной составляющей внутренней мотивации. Л.В. Альмяшова, О.В. Митякина рассматривают положительное 
влияние внеучебной научно-познавательной деятельности на мотивацию учащихся технических вузов к изучению иностранных языков на примере немецкого и английского языков [12]. Ю.Л. Казакова приводит в пример учебно-телекоммуникационные проекты как возможный способ развития мотивации при изучении иностранного языка. Она подчеркивает важность сети Интернет при обучении иностранному языку, рассматривая указанную сеть как доступный источник информации и естественную языковую среду [13].

Опыт Ю.Л. Казаковой, Л.В. Альмяшовой и других показывает эффективность познавательного вида внеучебной деятельности в качестве мотиватора к изучению иностранного языка. В данной же работе рассматривается пример развлекательно-досуговой деятельности, которая с большей вероятностью приводит к получению удовольствия, а это может служить более прочной основой для формирования внутренней мотивации к изучению иностранного языка. Мотивация на всех этапах развития личности играет значительную роль, поскольку механическое заучивание дает несравнимо меньший эффект, чем изучение осознанное, сосредоточенное, целенаправленное.

Как было отмечено выше, проблемное моделирование как подход имеет значительный мотивационный потенциал, следовательно, условиями проблемного моделирования будут являться:

- вариативность содержания профильных учебных дисциплин;

- взаимная интерактивность (в режимах студент - студент, студент - группа, студент - преподаватель, группа - преподаватель);

- индивидуализация обучения (личностная образовательная траектория каждого студента);

- нелинейность прохождения учебного материала;

- параллельное и концентрическое изучение материала профильных учебных дисциплин и производственных практик.

Выделим условия применения мультимедиа-технологий в рамках проблемного моделирования:

1) наличие доступа к сети Интернет;

2) наличие специально оборудованных помещений для проведения занятий;

3) учет отрицательных последствий внедрения мультимедийных технологий в образовательный процесс;

4) наличие у преподавателя определенных знаний, умений, навыков и компетенций в области применения средств цифровой педагогики;

5) моделирование индивидуальной образовательной траектории обучающегося средствами интерактивности; 
6) составление перечня отрабатываемого материала (определение тем, подлежащих усвоению только с помощью мультимедиа-технологий);

7) выявление причин отторжения медиа-воздействия и презентация анализа коллегам; 8) разработка преподавателем учебных электронных курсов с практикоориентированными заданиями с целью моделирования будущей профессиональной деятельности с использованием мультимедиа-технологий.

Приведем примеры практико-ориентированных заданий с применением мультимедиатехнологий в условиях проблемного моделирования:

1) разработайте веб-страницу, презентацию, облако тегов (на выбор) по теме: «Подготовка устного переводчика к работе со специальной лексикой»;

2) используя онлайн-сервис Prezi (Руководство пользователя по работе с Prezi http://oprezi.ru/o-prezi.html), создайте презентацию по теме: «Анализ веб-сайта для изучения иностранного языка (в помощь студенту, школьнику, переводчику)»;

3) разработайте глоссарий понятий по выбранной вами теме на платформе Quizlet (https://quizlet.com);

4) используя платформу Ding Talk, создайте группу для обучения (выберите одно направление (лексика, фонетика, грамматика), разработайте систему занятий;

5) предложите методическую разработку по применению газетно-информационных материалов на уроках английского языка в старшей школе (Используя конструктор онлайнопросов и викторин Mentimeter.com, студенты предлагают свою методическую разработку. Так студенты изучают тему по теории и практике перевода как учебной профильной дисциплины и пополняют свою педагогическую копилку, свое профессиональное портфолио новыми интерактивными и современными средствами);

6) используя конструктор тестов OnlineTestPad (справочная информация об основах конструктора тестов), создайте тест по иностранному языку.

Следует отметить, что внедрение мультимедиа-технологий в рамках проблемного моделирования как подхода может происходить на разных этапах обучения.

\section{Выводы}

Таким образом, мы приходим к следующим выводам:

- проблемное моделирование как новый авторский подход в обучении имеет значительный потенциал для развития профессиональных компетенций;

- проблемное моделирование и мультимедийные технологии обучения неразрывно связаны и оказывают стимулирующее влияние на развитие профессиональной траектории;

- внедрение мультимедийных технологий при изучении дисциплин профильного цикла несет значительный вклад в развитие профессиональных навыков в процессе обучения; 
- обучение в рамках проблемного моделирования с применением мультимедийных технологий может значительно повысить уровень мотивации обучающихся.

Перспективы дальнейшего исследования проблемы мы видим в более детальном изучении проблемного моделирования в подготовке студента к непосредственной профессиональной деятельности, а также в разработке диагностического инструментария с применением мультимедиа-технологий с целью активизации самостоятельной практикоориентированной работы студентов.

\section{Список литературы}

1. Арстанов М. Ж., Пидкасистый П. И., Хайдаров Ж. С. Проблемно-модельное обучение: вопросы теории и технологии. Алма-Ата: Мектеп, 1980. 226 с.

2. Coorough C. Multimedia and the Web: creating digital excitement. Calleen Coorough. Orlando, FL: Harcourt College Publishers, 2001. 362 p.

3. Фоминых М.В. Особенности педагогического взаимодействия в условиях проблемномодельного подхода // Высшее образование сегодня. 2017. № 1. С.11-12.

4. Баранова Е.В. Психологические детерминанты формирования иноязычной компетенции в старшем школьном возрасте // Достижения вузовской науки. 2016. № 25-1. С. 75-80.

5. Зайцев В. С. Мультимедийные технологии в образовании: современный дискурс. Челябинск: Издательство ЗАО «Библиотека А. Миллера», 2018. 30 с.

6. Интерактивные технологии в образовании // Учебно-методический комплекс, Российский государственный гуманитарный университет. М., 2005. 21 с.

7. Кущева Н.Б., Терехова В.И. Современная цифровая образовательная среда в высшем образовании России // Проблемы современной экономики. 2018. № 1 (65). С. 191-194.

8. Пузейкина Л.Н., Бояркина А.В. Расширенные возможности преподавания иностранного языка в вузе с использованием систем дистанционного обучения (на примере курсов сетевого сопровождения аудиторных занятий по немецкому языку) // Педагогика. Психология. Философия. 2018. № 4 (12). С. 61-70.

9. Мамарасулов У.Г. Мотивация - ключ к успеху в процессе обучения иностранному языку (на примере немецкого языка) // Молодой ученый. 2012. № 4. С. 432-434.

10. Болбаков Р.Г. Мультимедийные образовательные технологии // Управление образованием: теория и практика. 2015. № 1 (17). С. 156-167.

11. Деньгина М.Р. Мотивация в обучении иностранным языкам // Общество, наука, инновации (НТК-2012): сборник материалов: Общеуниверситетская секция, БФ, ГФ, ФЭМ, 
ФАВТ, ФАМ, ФПМТ, ФСА, ХФ, ЭТФ. Ответственный редактор: Литвинец С.Г., 2012. С. 582586.

12. Альмяшова Л.В., Митякина О.В. Преподавание иностранного языка в техническом вузе: организация внеаудиторной работы как развитие положительной мотивации // Lingua mobilis. 2012. T. 6. № 39. C. 124-129.

13. Казакова Ю.Л. Международный телекоммуникационный проект как эффективный способ формирования коммуникативной компетенции школьников и повышения мотивации к изучению иностранного языка // Психология и педагогика: методика и проблемы практического применения. 2011. № 20. С. 363-367. 